\title{
Performance assessment of bi-directional knotless tissue-closure devices in juvenile Chinook salmon surgically implanted with acoustic transmitters
}

\author{
Christa M Woodley ${ }^{1 * \dagger}$, Katie A Wagner ${ }^{2 \dagger}$, Amanda J Bryson ${ }^{1}$ and M Brad Eppard ${ }^{3}$
}

\begin{abstract}
Background: Acoustic transmitters used in telemetry studies to assess fish migration and survival are often surgically implanted into the coelomic cavity of the fish. While intra-coelomic implantation is a well-established method, the surgical process and/or implanted device may affect the health, behavior and survival of the fish under investigation, thus affecting study results. Tag effect research has focused on minimizing the aforementioned effects and continues to look for novel solutions. The first use of bi-directional knotless (barbed) suture material in fish occurred in 2009 to close incisions in juvenile Chinook salmon (Oncorhynchus tshawytscha). The suture barbs eliminate the need for knots, thereby reducing surgical time and concomitantly anesthetic and handling time for the fish. The bi-directional knotless suture had higher transmitter retention compared to the monofilament material, which was in a simple interrupted pattern. However, the incisions closed with bi-directional knotless sutures had an increased occurrence of ulceration and erythema. The objective of this study was to refine the suturing patterns of the bi-directional knotless suture used in 2009 by altering the needle size and retest suture performance in juvenile Chinook salmon. We examined the effects from the bi-directional knotless suture using three different suture patterns and two needle lengths: 6-Point (12-mm needle length), Wide " $\mathrm{N}$ " (12-mm needle length), Wide " $\mathrm{N}$ " Knot 12 (12-mm needle length), and Wide "N" Knot 18 (18-mm needle length).

Results: Using a performance rank index of observed metrics (mortality, transmitter expulsion, suture functionality, incision openness, ulceration and erythema), the Wide " $N$ " Knot 12 suture pattern had an overall better performance than the other needle types and suture patterns. All needle types and suture patterns resulted in poor suture functionality by Day 14. The 6-Point, Wide " $\mathrm{N}$ " and Wide " $\mathrm{N}$ " Knot 18 treatments had no functional sutures by the end of the study; while the Wide "N" Knot 12 treatment had 33\% functional sutures.

(Continued on next page)
\end{abstract}

\footnotetext{
* Correspondence: christa.woodley@pnnl.gov

'Equal contributors

'Pacific Northwest National Laboratory, 1529 W Sequim Bay Rd., Sequim, WA 98382, USA

Full list of author information is available at the end of the article
} 


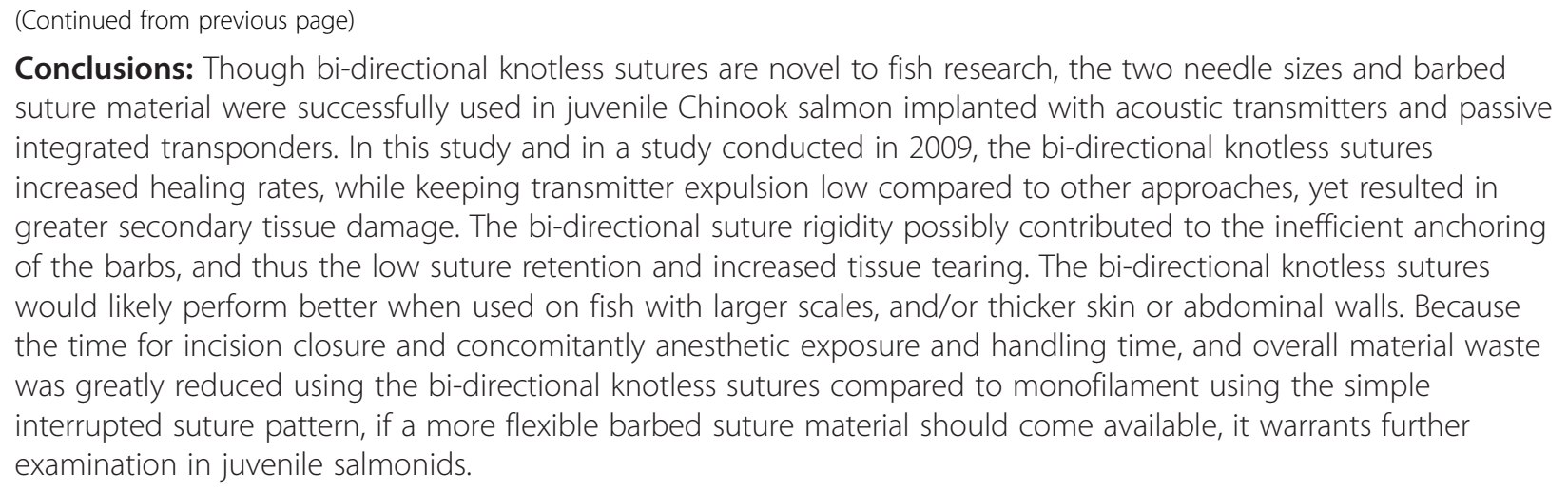

Keywords: Surgery, Salmonids, Biotelemetry, Bio-effect

\section{Background}

Acoustic telemetry has become a commonly used tool for monitoring migratory patterns, habitat preferences and survival of fish [1-3]. Telemetry studies utilize an array of cabled and autonomous receivers to detect acoustic signals emitted by acoustic transmitters for tracking the location of fish in the river [1-3]. These acoustic transmitters are implanted, either externally or internally, on the species of interest. Internal surgical implantation, such as intra-coelomic implantation, is often the preferred method of attachment for survival and behavior studies as it increases long-term transmitter retention and places the transmitter near the center of gravity of the fish, reducing drag [4,5]. Analytical models using telemetry technology to estimate survival and predict behavior assume tagged fish are representative of the population under investigation and that neither the transmitter nor the tagging process elicits behavioral, physiological or survival differences [6]. While surgical implantation is a well-established technique, the surgical process or attached transmitter can alter the behavior, growth or survival of the fish [7-10].

The surgical implantation process is inherently invasive, because it requires the incising of the abdominal wall and implantation of tags into the coelomic cavity. Incised tissue increases the likelihood of osmotic stress, infection and susceptibility to pathogens [11]. Optimally, incision closures reduce open spaces and closely align the incised tissue margins (that is, edges of the incised tissue) to increase the rate of healing, while keeping osmotic stress, infection and susceptibility to pathogens low [11-13]. In order for incision margins to stay approximated, the sutures must remain functional. A "functional suture" applies proper tension across the wound, remains knotted, and does not tear through the body wall (modified from Deters [14]). For incision closures, many fishery studies use synthetic absorbable monofilament suture placed in a double or single simple interrupted suture pattern $[2,12]$. The tension across the incision, using this material and the simple interrupted suture pattern, is focused on each individual suture site and thus, creates the potential for incision gapping (openness) and subsequently stress, infection and transmitter expulsion.

Transmitter expulsion can occur from a foreign body rejection response, poor incised tissue apposition [15], incision openness from suture loss [16], or high tag burden (that is, the weight of the transmitter in relation to the weight of the fish) [10]. External forces, such as pressure, can also facilitate transmitter expulsion from turbine passage or plunge pool [17]. Expulsion of transmitters, regardless of the reason, can result in studies violating assumptions of many telemetry models. Unaccounted for expelled transmitters whether from poor surgical procedures, normal physiological processes, or the failing health of the fish will appear as a non-detected individual, and thus is assumed to be a mortality. Inflated mortality rates, in particular for migration and survival studies, can lead to erroneous conclusions and affect management of the species or the watersheds. Thus, proper incision closure reduces adverse health effects and transmitter expulsion, thereby increasing the rate of healing and overall survival $[5,11]$.

Over the past 20 years, several materials and techniques were examined to close wounds and incisions from the implantation of telemetry devices in fishes. Staples and glue (cyanoacrylate) were easy to place and reduced handling and anesthetic time [18-20]; though, each had limitations. Studies using staples have reported good incision healing [19]; however, other studies have reported increased mortality and transmitter expulsion $[20,21]$. Cyanoacrylate was reported to successfully close incisions; yet some studies indicated that wounds dehisced, and the occurrence of tissue inflammation and necrosis increased $[7,22,23]$. Monofilament patterns have also been examined for incision closure, reopening and 
bio-effects, and research efforts have resulted in the monofilament suture in a simple interrupted suture pattern being a commonly used surgical technique for incision closure in fish [7,12,14,24,25]. Though used less often, continuous suture patterns offer the ability to reduce the number of knots, suture ends and suture surface area (externally); and are faster to deploy once skills are acquired [26,27].

For humans, a novel knotless bi-directional tissueclosure device (Monoderm $^{\mathrm{Tm}}$, Quill, Angiotech Pharmaceuticals, Vancouver, BC, Canada; Figure 1 [28,29]) (herein referred to as "barbed sutures") was designed to provide uniform tension across the wound, thereby bringing the incised tissue into closer approximation and decreasing healing time [27,30]. Barbed sutures have been demonstrated to be beneficial alternatives to monofilament sutures for internal surgeries, such as laparoscopic [31] and facial reconstructive surgeries [27], and successfully used externally for cosmetic skin closure [32]. This novel material allows for a continuous suture pattern that distributes the suture tension across the incised tissue more evenly, provides anchored points across the incision, and reduces instrument handling, surgical time, and time under anesthesia when compared to other suture material and patterns in humans [26,33].

Given the variation and need to minimize transmitter and tagging effects for telemetry studies, in 2009, barbed sutures were investigated in juvenile Chinook salmon (Oncorhynchus tshawytscha) as a novel approach to close surgical incisions from acoustic transmitter implantation. In the Pacific Northwest of the United States, large telemetry studies on the Columbia River tag upwards of 30,000 fish in one season for a single study [2]; therefore, the ability to reduce handling, anesthetic and surgical exposure is beneficial to the species of interest. In addition, techniques that can minimize tool use and the number of steps needed to complete a surgery increase the large project efficacy. Woodley et al. [34] found that the barbed suture material and tested suture

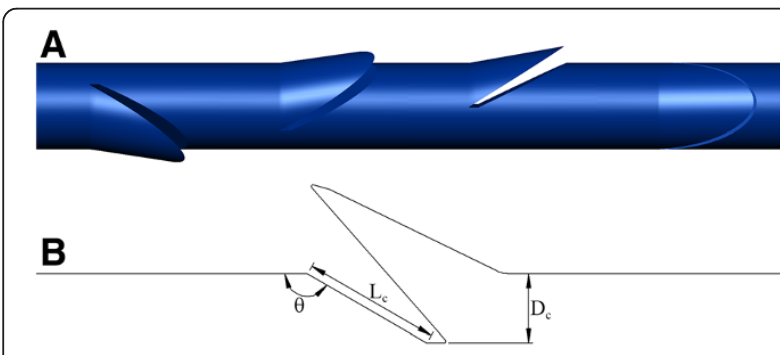

Figure 1 Bi-directional knotless suture. A) Magnified photo of Quill ${ }^{T M}$ bi-directional knotless suture (modified from Quil| ${ }^{T M}$ [28]). B) Geometry of individual barb (modified from Leung [29]). patterns were an average of 20 to $40 \%$ faster to place (depending on the pattern) than the traditional monofilament (two simple interrupted patterns with a $2 \times 2 \times$ $2 \times 2$ knot) and resulted in a lower number of expelled transmitters for fish held at $17^{\circ} \mathrm{C}$. However, erythema and ulceration occurred by Day 7 post-surgery at $12^{\circ} \mathrm{C}$ and overall suture functionality for the barbed suture was inferior to the monofilament suture in the simple interrupted suture pattern [34].

In this study, we further investigated the use of the barbed suture material and associated patterns in juvenile salmon by testing different needle sizes to decrease the cutting action of the needle and consequently increase the knotless suture anchoring ability. The aim of this study was to compare the barbed suture performance on groups of juvenile Chinook salmon (CHK) using treatments featuring three suture patterns and two needle sizes: 6-Point (12-mm needle length), Wide "N" (12-mm needle length), Wide "N" Knot 12 (12-mm needle length) or Wide "N" Knot 18 (18-mm needle length).

\section{Results}

\section{Mortality and transmitter expulsion}

The mortality rate for surgically implanted fish was low (4.8\%); only one fish in the 6-Point treatment died at 10 days post-surgery. There were no significant differences in mortality rates between treatments $(P>0.05)$. Passive integrated transponders (PITs) were not expelled. Acoustic transmitters (ATs; Table 1) were expelled, though, not significantly different between treatments $(P>0.05)$.

\section{Incision healing}

On Day 7, each treatment exhibited incision openness (Table 1), yet there were no significant differences in the measured area of the incision openness $(P>0.05)$. Fish size and, accordingly, tag burden were not predictors of incision openness (fork length (FL): $P>0.05$; wet weight (WW): $P>0.05$ ). Incisions closed with the 6-Point suture pattern had a significantly greater frequency of ulceration (100\%), followed by the Wide "N" Knot 12 (50\%), Wide "N" Knot 18 (33\%) and the Wide "N" (17\%) suture patterns $(P<0.01$; Table 1$)$, but the measured ulcerated surface area did not vary with treatment $(P>0.05)$. Incisions closed with the 6-Point and Wide "N" Knot 18 suture patterns had a significantly greater frequency of erythema $(100 \%$; all $P<0.01)$ than those closed with the Wide "N" Knot 12 (67\%) and Wide "N" (33\%) suture patterns (Table 1). Total erythema was significantly greater in the Wide " $\mathrm{N}$ " Knot 18 treatment $(P<0.05)$ than in the Wide "N" treatment.

By Day 14, only one fish from the Wide "N" Knot 12 treatment exhibited incision openness $\left(7.12 \mathrm{~mm}^{2}\right)$, which was attributed to the AT protruding halfway through the incision. Incision openness was not significantly different 
Table 1 Observed metrics for each suture pattern treatment

\begin{tabular}{llllll}
\hline Observation & Day & 6-Point & Wide “N" & Wide “N" Knot 12 & Wide “N" Knot 18 \\
\hline Expelled transmitters & 14 & $0 \%$ & $33 \%$ & $0 \%$ & $33 \%$ \\
Incision openness & 7 & $0.59 \pm 1.10$ & $2.86 \pm 3.01$ & $1.05 \pm 2.17$ & $2.37 \pm 4.10$ \\
Ulceration & 14 & $0.00 \pm 0.00$ & $0.00 \pm 0.00$ & $7.12 \pm 0.0$ & $0.00 \pm 0.00$ \\
Erythema & 7 & $1.99 \pm 2.28$ & $0.02 \pm 0.06$ & $1.04 \pm 1.73$ & $0.25 \pm 0.36$ \\
& 14 & $0.00 \pm 0.00$ & $0.00 \pm 0.00$ & $0.29 \pm 0.41$ & $0.30 \pm 0.29$ \\
\hline
\end{tabular}

The frequency of occurrence as a percentage for transmitter expulsion is shown for each treatment. The average area \pm SD for incision openness, ulceration and erythema on each observation day for each treatment is shown for each treatment.

between treatments $(P>0.05)$, but incision openness as a function of fish size was not analyzed on Day 14, because only one fish exhibited incision openness. Incisions closed with the Wide "N" Knot 18 suture pattern had a significantly greater frequency of ulceration $(67 \%)$ compared to the Wide "N" Knot 12 (50\%), Wide "N" $(0 \%)$ and 6-Point $(0 \%)$ suture patterns $(P<0.05$; Table 1$)$, but measured ulcerated surface area did not vary among treatments $(P>0.05)$. The frequency and measured area of erythema did not vary with treatment $(P>0.05$; Table 1).

\section{Suture functionality}

On Day 7, each treatment had fish with nonfunctional sutures at all paired suture sites (Table 2). The Wide "N" Knot 12 (50\%) and Wide "N" Knot 18 (33\%) treatments had significantly more functional sutures at site 1 than the 6-Point and Wide " $\mathrm{N}$ " $(0 \%)$ treatments (all $P<0.05)$. At site 2, each treatment had fish with non-functional sutures, but frequency did not vary with suture pattern $(P>0.05)$. At site 3, the 6-Point treatment had 33\% functional sutures.

By Day 14, 93\% of all sutures were non-functional (Table 2). The Wide "N" Knot 12 had significantly more functional sutures than the 6-Point, Wide " $N$ " and Wide "N" Knot 18 treatments at site $1(P<0.05)$ and site $2(P<0.05)$. At site 3 , the 6-Point treatment had no functional sutures.

Table 2 Frequency of functional sutures by paired suture site for each suture pattern treatment

\begin{tabular}{llllll}
\hline $\begin{array}{l}\text { Observation } \\
\text { day }\end{array}$ & Site & 6-Point & Wide “N" & $\begin{array}{l}\text { Wide “N" } \\
\text { Knot 12 }\end{array}$ & $\begin{array}{l}\text { Wide “N" } \\
\text { Knot 18 }\end{array}$ \\
\hline \multirow{3}{*}{7} & 1 & $0 \%$ & $0 \%$ & $50 \%$ & $33 \%$ \\
& 2 & $0 \%$ & $0 \%$ & $50 \%$ & $0 \%$ \\
& 3 & $33 \%$ & $N A$ & $N A$ & NA \\
14 & 1 & $0 \%$ & $0 \%$ & $17 \%$ & $0 \%$ \\
& 2 & $0 \%$ & $0 \%$ & $33 \%$ & $0 \%$ \\
& 3 & $0 \%$ & $N A$ & $N A$ & NA \\
\hline
\end{tabular}

Suture functionality was not significantly related to total incision openness on Day $7(P>0.05)$. Conversely, on Day 14, suture functionality was significantly related to incision openness $(P<0.05)$. These contradictory results are likely confounded by tag bulging in the Wide " $N$ " Knot 12 treatment by Day 14 and the small sample size.

\section{Performance index}

Each examined frequency response was ranked $(1=$ best to $4=$ worst) to provide an integrative assessment of each suture pattern (Table 3). Although the Wide "N" Knot 12 treatment performed better, overall performance was not significantly different between treatments $(P>0.05)$.

\section{Discussion}

The objective of this study was to assess the performance of the barbed suture, needle types and suture patterns for use on juvenile Chinook salmon surgically

Table 3 Performance index based on the rank of each measured treatment observation

\begin{tabular}{|c|c|c|c|c|}
\hline \multirow[b]{2}{*}{ Measured observation } & \multicolumn{4}{|c|}{ Treatment } \\
\hline & 6-Point & $\begin{array}{l}\text { Wide } \\
\text { "N" }\end{array}$ & $\begin{array}{l}\text { Wide "N" } \\
\text { Knot } 12\end{array}$ & $\begin{array}{l}\text { Wide "N" } \\
\text { Knot } 18\end{array}$ \\
\hline Mortality & 4 & 2 & 2 & 2 \\
\hline ATs expelled & 1.5 & 3.5 & 1.5 & 3.5 \\
\hline Presence of openness, Day 7 & 2 & 4 & 2 & 2 \\
\hline Functional suture, Site 1, Day 7 & 3.5 & 3.5 & 1 & 2 \\
\hline Functional suture, Site 2, Day 7 & 3 & 3 & 1 & 3 \\
\hline $\begin{array}{l}\text { Presence of ulcerated areas, } \\
\text { Day } 7\end{array}$ & 4 & 1 & 3 & 2 \\
\hline $\begin{array}{l}\text { Presence of ulcerated areas, } \\
\text { Day } 14\end{array}$ & 1.5 & 1.5 & 3 & 4 \\
\hline $\begin{array}{l}\text { Presence of erythema areas, } \\
\text { Day } 7\end{array}$ & 3.5 & 1 & 2 & 3.5 \\
\hline $\begin{array}{l}\text { Presence of erythema areas, } \\
\text { Day } 14\end{array}$ & 1 & 2.5 & 2.5 & 4 \\
\hline Average & 2.67 & 2.44 & $2.00^{(a)}$ & 2.89 \\
\hline
\end{tabular}


implanted with ATs and PITs. We examined six measures including mortality, AT expulsion, incision openness, suture functionality (presence and tension), ulceration and erythema. These measures were used to determine an overall performance ranking for each tested needle size and suture pattern. Suture pattern influenced suture performance more than needle size. Overall, all the patterns tested revealed that the incisions were closed within 14 days. Despite the lack of significant differences of some observed measures, the Wide "N" Knot 12 suture pattern and needle performed better overall than the other needle size and suture patterns. Even though the small sample size was a possible confounding factor on some statistical tests, the results were similar to tests conducted in 2009, where the barbed suture provided more uniform tension across the incision to speed the rate of healing, but at a cost of increasing secondary tissue damage.

The mortality rate for tagged fish was low, with only a single mortality occurring in the 6-Point treatment. Because this study was conducted at the end of the subyearling Chinook salmon migration window for run-of -the-river smolts and water temperatures were elevated, fish held at the facility for a concurrent study experienced high holding mortality rates [35]. Thus, the single mortality in this study may or may not be attributable to the suture type and pattern, but rather to other peripheral circumstances, such as poor condition, high water temperatures or individual progression into the smoltification cycle [36,37].

Analytical models used in telemetry studies can account for a known rate of transmitter expulsion to control for false mortality rates; therefore, transmitter expulsion was evaluated for each suture pattern and needle type. In this study, the overall transmitter expulsion rate was relatively low with $0 \%$ and $15 \%$ of PITs and ATs being expelled, respectively, for juvenile Chinook salmon when incisions were closed with barbed sutures. AT expulsion occurred in the Wide "N" and Wide "N" Knot 18 treatments. Although the 6-Point and Wide "N" Knot 12 treatments had superior transmitter retention, the low sample sizes likely prevented the detection of a significant difference between treatments. Comparatively, the AT expulsion rates were $0 \%$ and $6 \%$ by 28 days postsurgery using the 6-Point, Wide "N", and Wide "N" Knot 12 suture patterns for juvenile Chinook salmon held at 12 and $17^{\circ} \mathrm{C}$, respectively [34]. In addition, the barbed suture patterns had lower AT expulsion rates than Chinook salmon with incisions closed using Monocry ${ }^{\mathrm{m}}{ }^{\mathrm{m}}$ (Ethicon Inc., an Angelo, TX, USA) with two simple interrupted sutures (15.6\%), when fish were held at $17^{\circ} \mathrm{C}$ [34]. In other studies that used Monocryl ${ }^{\mathrm{Tm}}$ with two simple interrupted sutures to close incisions, the transmitter expulsion rates were similar $\left(12^{\circ} \mathrm{C}=1 \% ; 17^{\circ} \mathrm{C}=14 \%\right)$ at
14 days post-surgery with a similar sized AT $(12 \times 5.2 \times$ $3.8 \mathrm{~mm}, 0.43 \mathrm{~g}$ in air) [14]. However, a study using larger ATs $(21 \times 7 \times 6 \mathrm{~mm} ; 0.9 \mathrm{~g}$ in air) reported much higher expulsion rates $(37 \%)$ for juvenile Chinook salmon held at $17^{\circ} \mathrm{C}$ by 30 days post-surgery [37]. Therefore, the barbed suture in the 6-Point and Wide " $\mathrm{N}$ " Knot 12 suture patterns had better transmitter retention rates than those reported for the Monocryl ${ }^{\text {mi }}$ with two simple interrupted sutures [14,37].

For intra-coelomic implantation, the barbed suture was hypothesized to have greater efficacy compared to the Monocryl ${ }^{\mathrm{TM}}$ in a simple interrupted suture pattern, because barbed sutures provide more uniform tension and anchored points across the incision, increase incised tissue margin approximation and the rate of healing [27,30], and lessen the time under anesthesia [33]. Suture functionality and suture retention were lower than expected with the barbed suture than based on other research studies $[10,14,34]$. For example, the 6-Point treatment had only partially functional sutures, specifically only one of three sites retaining the suture by Day 7, and no functional sutures by Day 14. Because incision openness and transmitter expulsion tends to be inversely correlated to suture retention [14], one would expect high incision openness and transmitter expulsion in this study, which did not occur. On Day 7, the 6-Point treatment had the smallest area of openness (mean $0.59 \mathrm{~mm}^{2}$ ), likely due to the suture pattern providing better tension across the entire incision early in the healing process. By Day 14, the only incidence of openness was caused by an AT protruding through the incision in the Wide "N" treatment. These results indicate that even though the barbed suture has low retention with the tested patterns, the suture and patterns provide proper tension for approximating incision margins within the first few days post-surgery, thereby increasing the rate of healing and reducing incision openness.

In fish, incision healing involves a series of overlapping phases: inflammation, re-epithelialization, proliferation, organization and differentiation [11]. The healing process can be disrupted by pathogen entry $[11,38]$ or further tissue damage, resulting in irritation responses, such as inflammation, ulceration and erythema. In addition, irritation has been related to tissue trauma by the number of entry/ exit suture points and knot sizes [24,39]. In humans, tissue reactions were found to be similar between barbed suture wound closures and monofilament wound closures [32], similar results were found with the use of the barbed sutures in juvenile Chinook salmon [34]. Comparable to juvenile Chinook salmon held at $12^{\circ} \mathrm{C}$ [34], the juvenile Chinook salmon, in this study, with the 6-Point pattern exhibited the greatest amount of ulceration and erythema followed by fish whose incisions were closed with the knot patterns, and lastly the pattern with the least 
suture material exposed to the fish, the Wide "N" pattern.

The ulceration and erythema are attributable to the presence of sutures, because ulcerations and erythema had subsided by Day 14 when sutures were not present. The severity of ulceration and erythema appeared to be related to the amount of suture-to-skin contact and tissue trauma (entry/exit points or needle size). For example, the Wide " $\mathrm{N}$ " treatment had the smallest frequency and surface area of ulceration and erythema and the lowest suture-to-skin contact and/or tissue trauma. Once a portion of the knotless suture failed, the functioning barbs held the rest of the suture in place and kept most (and often the middle) of the incision closed. Unlike barbed sutures, the knot in a simple interrupted suture pattern is the weakest point of the suture and the knot failing leads to the entire suture failing and thus there is no structural tension to approximate the incision edges [26]. The tissue irritation, seen in this study, was likely related to 1 ) the drag created by the suture material hanging out of the fish (Figure 2A), 2) tissue "bunching", resulting from barbs moving during swimming (Figure 2B), and 3) the barbs tearing the tissue immediately around the needle entry/exit points (Figure $2 \mathrm{C}$ ).

Although monofilament placed in a simple interrupted suture pattern is an effective technique for incision closure in juvenile salmonids, new closure techniques still warrant testing to improve tagging efficacy. Tagged fish benefit from reduced anesthetic and handling times and increased healing rates. Telemetry studies also benefit if the fish receive less stress and trauma from surgery and/ or the better retention of transmitter(s). Regardless of the needle size, the bi-directional knotless suture still had complications, such as the increased secondary tissue damage, similar to Woodley et al. [34]. However, the bi-directional knotless suture proved to be a superior method, opposed to interrupted sutures, for many internal and external surgical techniques in humans as it reduces surgical time and increases the rate of healing

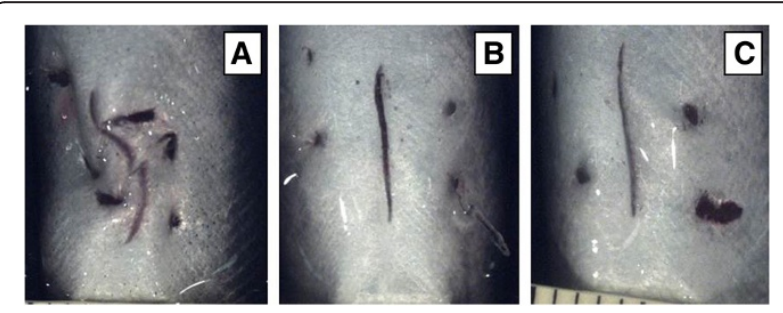

Figure 2 Ulceration and erythema examples from the 6-Point and Wide "N" treatments, Day 7. A) 6-Point suture pattern where the suture is tightening, tearing the tissue towards the incision. B) Wide "N" pattern in CHK where the suture has slipped out of the fish creating drag. C) Wide " $\mathrm{N}$ " pattern where the suture has slipped out or pulled into the fish leaving a torn or rubbed area associated with entry and exit points.
$[27,33]$, while maintaining wound strength similar to that of monofilament sutures [32].

\section{Conclusions}

At this time, we do not recommend the use of the bidirectional knotless sutures in juvenile Chinook salmon (FL range 115 to $132 \mathrm{~mm}$ ) for closing surgical incisions associated with telemetry studies. Telemetry and survival studies are based on the assumption that the tagged fish are representative of the population under investigation and that the transmitter or tagging process does not alter the physiology or survival of the fish. While this suture and associated patterns appear to increase the rate of healing, the suture itself has low retention and causes high secondary tissue damage when part of the suture fails. The delicate dermal tissue of juvenile Chinook salmon or the suture geometry may have influenced the appearance of secondary tissue damage [40]. Unlike monofilament suture, once a portion of the suture fails, the barbed suture can still remain functional and keep the incision closed, but subsequently increases secondary tissue damage. This suture may be more appropriate for use with larger fish or fish with larger scales, although this has not been tested. A smaller, more flexible suture and barb geometry may be required for better anchoring and retention in juvenile salmonids.

\section{Methods}

\section{Fish acquisition}

In summer 2010, run-of-the-river juvenile CHK $(\mathrm{N}=27)$ were collected at the John Day Dam Smolt Monitoring Facility (SMF; rkm 349). Fish (FL range $=115$ to $132 \mathrm{~mm}$; mean $\mathrm{FL}=122 \mathrm{~mm}$; WW range $=10.1$ to $22.7 \mathrm{~g}$; mean $\mathrm{WW}=15.3 \mathrm{~g}$ ) were held for 24 hours in $378.5-\mathrm{L}$ circular tanks supplied with flow-through river water and supplemental oxygen and then transported to the Bonneville Dam SMF. Fish were transported by truck in a $378.5-\mathrm{L}$ Bonar $^{\text {TM }}$ tote (Bonar Plastics, Chicago, IL, USA) equipped with supplemental oxygen. Dissolved oxygen and water temperature were monitored during transportation to ensure that appropriate levels were maintained. At the Bonneville Dam SMF, fish were placed in 302.8-L tanks supplied with flow-through river water. Fish were fed Biodiet pellets (Bio-Oregon, Inc., Longview, WA, USA) daily at a rate of $1.1 \%$ of their body weight and kept on a natural photoperiod. Tanks were siphoned daily to remove fecal matter and debris. At the start of the experiment, the ambient river temperature was $19.8^{\circ} \mathrm{C}$, but had reached $22.5^{\circ} \mathrm{C}$ by the end of the experimental period (mean temperature $=21.5^{\circ} \mathrm{C}$ ).

\section{Suture patterns and mechanics}

All suture patterns were performed with Monoderm ${ }^{\mathrm{TM}}$ Quill tissue closure devices (Angiotech Pharmaceuticals, 
Vancouver, BC, Canada). Tissue-closure devices are absorbable monofilament sutures with tissue retainers (barbs) arranged around the shaft that protrude at approximately 45 degrees from the main suture shaft (Figure 1). The barbs anchor into the tissue, eliminating the need for a knot.

Fish were randomly assigned to one of five treatments (Figure 3):

1) 6-Point $(\mathrm{N}=6$; Figure $3 \mathrm{~A})$ - This suture pattern was continuous and had smaller angles across the incision and more insertion points than the other treatments. The needle entered through the incision and exited at point $\mathrm{X}_{1}$ until the middle point of the

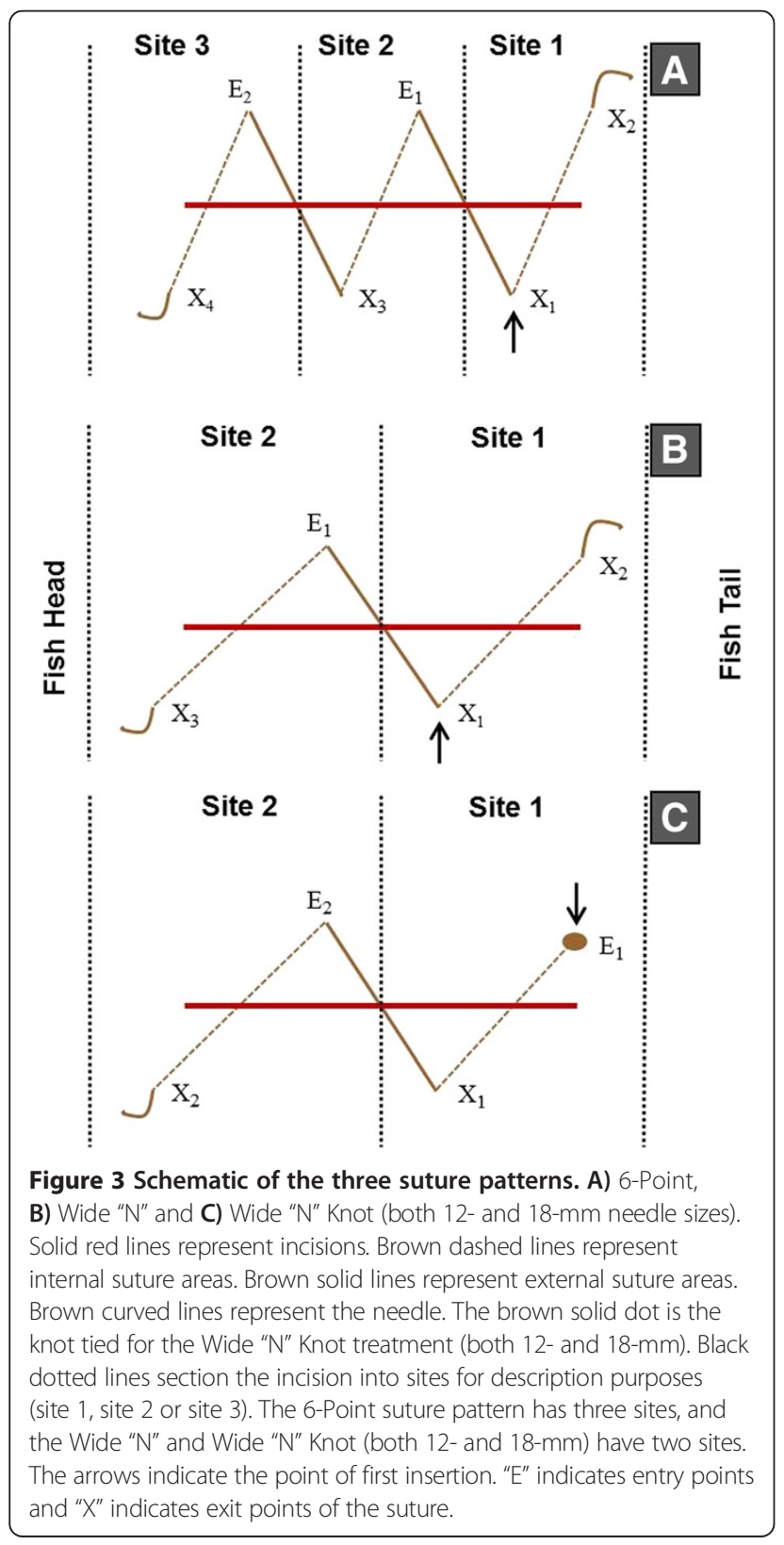

suture was through the skin to ensure barbs were anchored in both directions. The internal portion of the suture exited through point $\mathrm{X}_{2}$. Next, the external portion of the suture at point $\mathrm{X}_{1}$ entered through point $E_{1}$, exited at point $X_{3}$, entered at point $E_{2}$ and exited at point $X_{4}$. Excess suture was cut, leaving a 3-mm tail at both ends (Figure 4A). The 6-Point treatment used a 3-0, 3/8 circle diamond point needle (12-mm length).

2) Wide "N" ( $\mathrm{N}=6$; Figure $3 \mathrm{~B})$ - This pattern was continuous and had wider angles across the incision and fewer insertion points than the 6-Point treatment. The needle entered through the incision and exited at point $X_{1}$ until the middle of the suture was through the skin to ensure barbs were anchored in both directions. The internal portion of the suture exited through point $\mathrm{X}_{2}$. Next, the external portion of the suture at point $X_{1}$ entered through point $E_{1}$ and exited through point $\mathrm{X}_{3}$. Excess suture was cut, leaving a $3-\mathrm{mm}$ tail at each end (Figure $4 \mathrm{~B}$ ). The Wide "N" treatment used a 3-0, 3/8 circle diamond point needle (12-mm length).

3) Wide "N" Knot 12 ( $\mathrm{N}=6$; Figure 3C) - This treatment pattern had the same angles across the incision as the Wide "N" suture pattern. Prior to suturing, a single square knot was placed at one end of the suture. The first point of insertion was at the posterior end of the incision at point $E_{1}$. The needle then exited at point $\mathrm{X}_{1}$, entered at point $\mathrm{E}_{2}$ and exited at point $\mathrm{X}_{2}$. Barbs gripped in one direction, opposite the knot. Excess suture was cut, leaving a 3-mm tail at point $X_{2}$. This technique is faster than placing a knot using a traditional suture and eliminates tissue tearing caused by knot tension. The Wide "N" Knot 12 treatment was performed using a 3-0, 3/8 circle diamond point needle (12-mm length).

4) Wide "N" Knot $18(\mathrm{~N}=3)$ - This treatment followed the same pattern as Wide "N" Knot 12 suture pattern, but used a 3-0,3/8 circle diamond point needle (18-mm length).

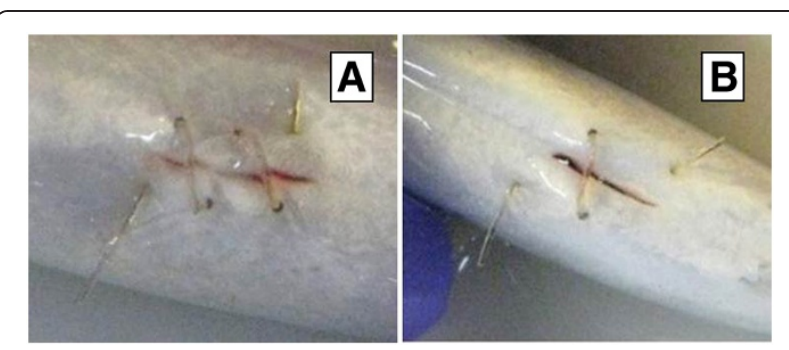

Figure 4 Day 0 suture patterns demonstrating the final product of the 6-Point and Wide "N" suture patterns. A) 6-Point suture pattern. B) Wide " $\mathrm{N}$ " suture pattern. The Wide " $\mathrm{N}$ " Knot (both 12- and 18-mm) suture pattern is similar. 
5) Control $(\mathrm{N}=6)$ - These fish were used to gauge mortality rates between treatments and underwent the same handling procedure as treatment fish but were not surgically implanted.

\section{Surgical procedure}

During surgery, average water temperature was $19.8^{\circ} \mathrm{C}$ $\left( \pm 2^{\circ} \mathrm{C}\right)$. To eliminate surgeon effects, one surgeon performed all surgeries. Surgical procedures followed those found in Woodley et al. [34]. Briefly, fish were anesthetized (stage 4 anesthesia [41]) in buffered $\left(\mathrm{NaHCO}_{3} ; 80 \mathrm{mg} / \mathrm{L}\right.$ water) tricaine methanesulfonate (MS-222; $80 \mathrm{mg} / \mathrm{L}$ water). Fish were then weighed (g), FL was measured $(\mathrm{mm})$, and both flanks were photographed. All fish were anesthetized and handled similarly regardless of treatment. Control fish bypassed the surgery stations and were placed into 5-gal recovery buckets (five fish per bucket), with aerated river water, and monitored during recovery from anesthesia. Fish receiving implants were placed ventral side up on the surgery table and given a maintenance dose of MS-222 (40 $\mathrm{mg} / \mathrm{L}$ water). A 5- to 7-mm incision was made along the linea alba between the pectoral fins and pelvic girdle. A PIT (hpt12; Biomark, Boise, ID, USA) and
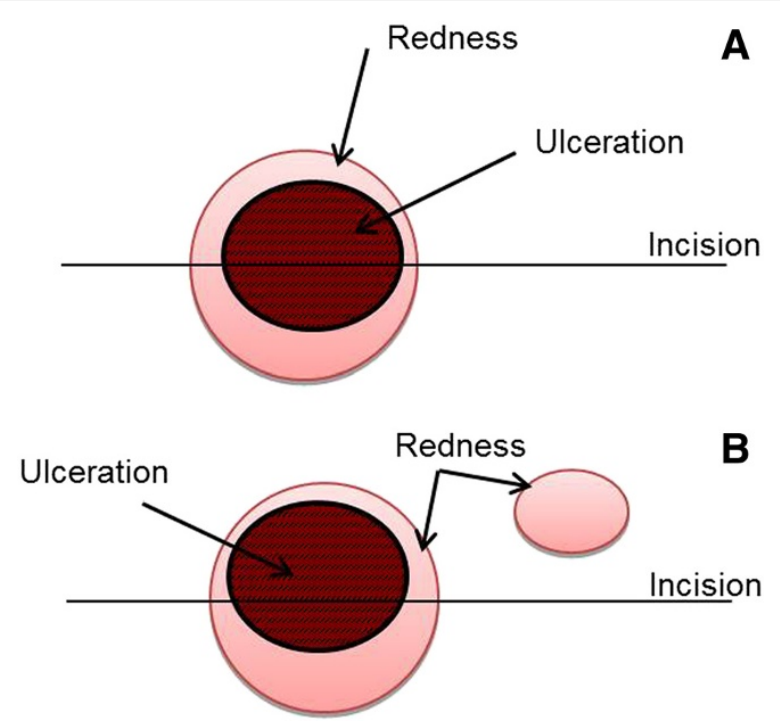

Figure $\mathbf{5}$ Incision erythema and ulceration differentiation.

Erythema was differentiated from ulceration by the consistency of the wound and area affected. In the above diagram, erythema scores would include the pink area, not the maroon-hashed area. Ulceration scores would include the maroon-hashed area (inner circles in $\mathbf{A}$ and $\mathbf{B}$ ) and not the pink areas. A) Only the pink area outer ring would be included in the erythema score. Any erythema in the ulcerated area was included in the ulceration score, not the erythema score. B) The erythema score would include the sum of pink areas for each wound or affected area. Ulcerations, if more than one, would be summed similarly. This approach allowed for the distinction between red inflamed areas and areas with exposed underlying tissue.
AT (each $12 \mathrm{~mm}$ long $\times 5 \mathrm{~mm}$ wide $\times 4 \mathrm{~mm}$ high, $0.43 \mathrm{~g}$ in air; Juvenile Salmon Acoustic Telemetry System) were then inserted into the coelomic cavity (mean tag burden $=3.58 \%$ ) and incisions were closed using a barbed tissue-closure device in one of the four suture pattern treatments, consisting of three suture patterns and two needle sizes (6-Point, Wide "N", Wide "N" Knot 12 or Wide "N" Knot 18). Surgical tools and tags were disinfected by soaking in ethanol for 10 minutes then rinsing with sterile water. After surgery, a photo was taken of the incision and fish were placed in recovery buckets until equilibrium was regained. Fish were then randomly placed and held in one of two circular tanks, equipped with flow-through river water, until examination.

\section{Response examinations}

Mortalities and transmitter expulsion were examined daily. PITs and ATs were only scored as expelled if the transmitter completely exited the fish. Incision healing (openness, ulceration and erythema) and suture functionality were examined 7 and 14 days post-surgery.

Incision examinations were partitioned into paired suture sites (that is, having an entry and exit point or two exit points; Figure 3$)$. The areas $\left(\mathrm{mm}^{2}\right)$ of incision openness, ulceration and erythema were quantified from photographs using Image J software (National Institutes of Health, Bethesda, MD, USA). Multiple areas of incision openness, ulceration or erythema were summed to

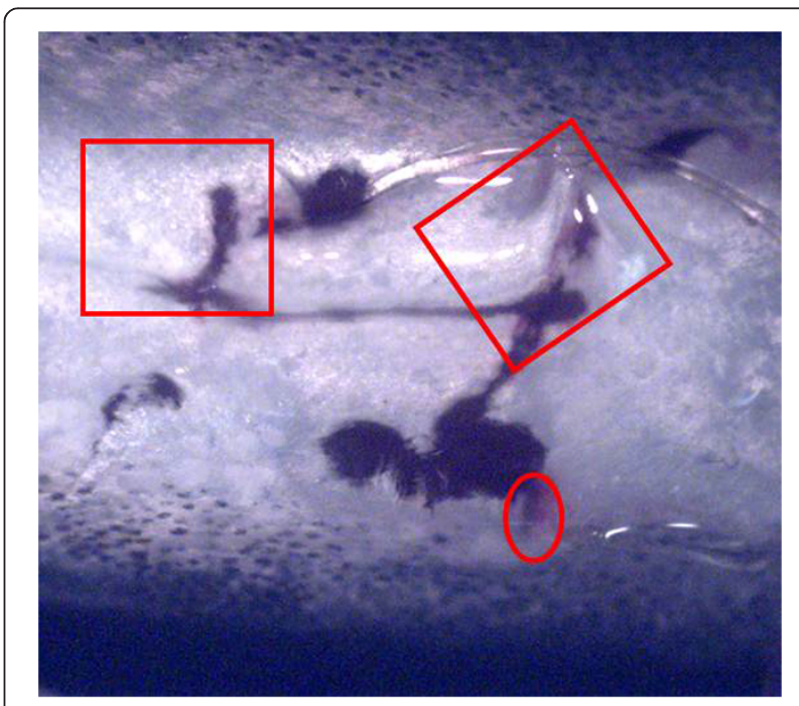

Figure 6 Example of ulceration and erythema due to suture tearing. The black circle highlights erythema not directly incorporated with ulceration. The black squares denote ulceration and erythema that were separated using Image J. The circle and square do not denote the actual Image J patterns and measurements used for the final summations of total ulceration and erythema. 
provide one value each for analyses (Figures 5 and 6). Sutures were deemed non-functional if they were absent or lacked tension to properly close the incision. Both suture presence and tension consistency were used to determine the suture functionality.

At the end of the study, all observations were ranked ( $1=$ best and $4=$ worst $)$ and scores were averaged to give an overall performance index. Ranks were assigned based on the presence of an observation. Treatments that tied for a certain observation rank were then given an averaged observation rank. For example, if three treatments had no mortalities and the fourth treatment had one or more mortalities, the fourth treatment group would be assigned a rank of 4 and the other three treatments would take ranks 1,2 and 3, which would be averaged to a final rank of 2 for each of the three treatments.

\section{Statistical analysis}

All data were analyzed using $\mathrm{R}$ statistical software (version 2.13.0, R Foundation for Statistical Computing, Vienna, Austria) and JMP (version 9; SAS, Cary, NC). Significance of each test was assessed based on an $\alpha$ of 0.05 . Binary data (mortality, tag loss, suture presence, suture tension, presence of ulceration, presence of erythema) were compared between suture patterns using a Fisher's Exact Test (FET). In this study, control fish were used only to gauge mortality rates; they were not used in other analyses. Continuous data (area of incision openness, ulceration and erythema) were analyzed for each observation day between suture patterns by a one-way analysis of variance (ANOVA). The performance index was analyzed for differences between suture treatments with an ANOVA. An ANOVA was used to test for differences in mean WW between fish in each treatment.

\begin{abstract}
Abbreviations
ANOVA: Analysis of variance; AT: Acoustic transmitter; FET: Fisher's exact test; FL: Fork length; PIT: Passive integrated transponder; SD: Standard deviation; SMF: Smolt monitoring facility; CHK: Chinook salmon; WW: Wet weight.
\end{abstract}

\section{Competing interests}

The authors declare that they have no competing interests.

\section{Authors' contributions}

CMW designed the study, was the project leader, and assisted with drafting the manuscript. KAW assisted with drafting the manuscript. AJB assisted with interpretation of results. MBE assisted with project support and drafting of the manuscript. All authors read and approved the final manuscript.

\section{Acknowledgements}

This project was funded by the U.S. Army Corps of Engineers, Portland, Oregon. The Pacific Northwest National Laboratory (PNNL) is operated by Battelle for the U.S. Department of Energy under contract DE-AC05-76RL01830. Funding for this study was secured through Richard S. Brown, PNNL. The statistics were conducted by Adam Seaburg and John Skalski, University of Washington. In addition, we thank Jayson Martinez for graphical support, Pacific States Marine Fisheries Commission employees Greg Kovalchuk, Dean Ballinger, and support scientists at John Day and Bonneville dams for their technical support and advice during the project. We also acknowledge the large project teams of the Lower Columbia River Acoustic-Tag Investigations of Dam Passage Survival and
Associated Metrics study (2010), without whose support this concurrent study could not have been accomplished. Lastly, we would like to thank our thorough reviewer and editor, Amoret Bunn and Susan Ennor, respectively, for their attention to details and excellent comments.

Animal facilities were certified by the Association for Assessment and Accreditation of Laboratory Animal Care, animals were handled in accordance with federal guidelines for the care and use of laboratory animals, and protocols were approved by the Institutional Animal Care and Use Committee, Battelle-Pacific Northwest Division (\#2010-10). References to trade names within do not imply endorsement by the U.S. Government.

\section{Author details}

${ }^{1}$ Pacific Northwest National Laboratory, 1529 W Sequim Bay Rd., Sequim, WA 98382, USA. ${ }^{2}$ Pacific Northwest National Laboratory, P.O. Box 999, Richland, WA 99352, USA. ${ }^{3}$ U.S. Army Corps of Engineers, Portland District, 333 SW First Ave, Portland, OR 97208, USA.

Received: 15 November 2012 Accepted: 3 May 2013

Published: 2 July 2013

\section{References}

1. McComas RL, Frost D, Smith SG, Ferguson JW, Carlson TJ, Aboellail T: A Study to Estimate Salmonid Survival Through the Columbia River Estuary Using Acoustic Tags, 2002. Final Report. Seattle, Washington: National Oceanic and Atmospheric Administration - National Marine Fisheries Service, Northwest Fisheries Science Center; 2005.

2. Hughes JS, Weiland MA, Woodley CM, Ploskey GR, Carpenter SM, Hennen MJ, Fischer ES, Greiner MJ, Cushing AW, Batten GW III, Deng Z, Etherington DJ, Fu T, Johnson GE, Khan F, Kim J, Martinez J, Mitchell TD, Rayamajhi B, Seaburg A, Skalski JR, Townsend RL, Zimmerman SA, Carlson TJ: Survival and passage of yearling and subyearling Chinook salmon and juvenile steelhead at McNary Dam, 2012. Army Corps of Engineers, Portland District, Portland, Oregon: Draft Report by Pacific Northwest National Laboratory to the U.S; 2013.

3. Clemens BJ, Clements SP, Karnowski MD, Jepsen DB, Gitelman Al, Schreck CB: Effects of transportation and other factors on survival estimates of juvenile salmonids in the unimpounded lower Columbia River. Trans Am Fish Soc 2009, 138:169-188.

4. Bridger CJ, Booth RK: The effects of biotelemetry transmitter presence and attachment procedures of fish physiology and behavior. Rev Fisheries Sci 2003, 11:13-34

5. Mulcahy DM: Surgical implantation of transmitters into fish. ILAE J 2003, 44:295-306

6. Peven C, Giorgi A, Skalski J, Langeslay M, Grassell A, Smith S, Counihan T, Perry R, Bickford S: Guidelines and suggested protocols for conducting, analyzing, and reporting juvenile salmonid survival studies in the Columbia River basin. Columbia Basin Research, Seattle: University of Washington; 2005.

7. Jepsen N, Koed A, Thorstad EB, Baras E: Surgical implantation of telemetry transmitters in fish: How much have we learned? Hydrobiologia 2002, 483:239-248.

8. LaCroix GL, Knox D, McCurdy P: Effects of implanted dummy acoustic transmitters on juvenile Atlantic salmon. Trans Am Fish Soc 2004, 133:211-220.

9. Bauer C, Loupal G: Common carp tissue reactions to surgically implanted radio tags with external antennas. J Fish Biol 2007, 70:292-297.

10. Chittenden CM, Butterworth KG, Cubitt KF, Jacobs MC, Ladouceur A, Welch DW, McKinley RS: Maximum tag to body size ratios for an endangered coho salmon (O. kisutch) stock based on physiology and performance. Environ Biol Fishes 2009, 84:129-140.

11. Fontenot DK, Neiffer DL: Wound management in teleost fish: biology of the healing process, evaluation, and treatment. Vet Clin N Am Exot Anim Pract 2004, 7:57-86.

12. Cooke SJ, Woodley CM, Eppard MB, Brown RS, Nielsen JL: Advancing the surgical implantation of electronic tags in fish: a gap analysis and research agenda based on a review of trends in intracoelomic tagging effects studies. Rev Fish Biol Fish 2011, 21:127-151.

13. Lin PH, Hirko MK, von Fraunhofer JA, Greisler HP: Wound healing and inflammatory responses to biomaterials. In Wound Closure Biomaterials and Devices. Edited by Chu CC, von Fraunhofer JA, Greisler HP. New York: CRP Press; 1996:7-24

14. Deters KA, Brown RS, Carter KM, Boyd JW, Eppard MB, Seaburg AG: Performance assessment of suture type, water temperature, and 
surgeon skill in juvenile Chinook salmon surgically implanted with acoustic transmitters. Trans Am Fish Soc 2010, 139:888-899.

15. Baras E, Westerloppe $L$ : Transintestinal expulsion of surgically implanted tags by African catfish Heterobranchus longifilis of variable size and age. Trans Am Fish Soc 1999, 128:737-746.

16. Panther JL, Brown RS, Gaulke GL, Deters KA, Woodley CM, Eppard MB: Influence of incision location on transmitter loss, survival, growth, and suture retention of juvenile Chinook salmon. Trans Am Fish Soc 2011, 140:1492-1503.

17. Stephenson JR, Gingerich AJ, Brown RS, Pflugrath BD, Deng Z, Carlson TJ, Langeslay MJ, Ahmann ML, Johnson RL, Seaburg AG: Assessing barotrauma in neutrally and negatively buoyant juvenile salmonids exposed to simulated hydro-turbine passage using a mobile aquatic barotrauma laboratory. Fish Res 2010, 106:271-278.

18. Mortensen DG: Use of staple sutures to close surgical incisions for transmitter implants. In Fish-Marking Techniques. Edited by Parker NC, Giorgi AE, Heidinger RC, Jester DB, Prince ED, Winans GA. Bethesda, MD: American Fisheries Society; 1990:380-383.

19. Swanberg TR, Schmetterling DA, McEvoy DH: Comparison of surgical staples and silk sutures for closing incisions in rainbow trout. N Am J Fish Manage 1999, 19:215-218.

20. Haeseker SL, Carmichael JT, Hightower JE: Summer distribution and condition of striped bass within Albemarle Sound, North Carolina. Trans Am Fish Soc 1996, 125:690-704.

21. Starr RM, Heine JN, Johnson KA: Techniques for tagging and tracking deepwater rockfishes. N Am J Fish Manage 2000, 20:597-609.

22. Peterson RW, Johnson DL: Notes: suitability of a cyanoacrylate adhesive to close incisions in black crappies used in telemetry studies. Trans Am Fish Soc 1991, 120:535-537.

23. Raoult V, Brown C, Williamson JE: Superglue is not super: an assessment of superglue for suturing tag incisions in a cultured marine fish. J World Aqua Soc 2012, 43:140-143.

24. Wagner GN, Stevens ED, Byrne P: Effects of suture type and patterns on surgical wound healing in rainbow trout. Trans Am Fish Soc 2000, 129:1196-1205.

25. Sandstrom PT, Ammann AJ, Michel C, Singer G, Chapman ED, Lindley S, MacFarlane, Klimley AP: Growth, survival, and tag retention of steelhead trout (Oncorhynchus mykiss) and its application to survival estimates. Environ Biol Fish 2013, 96:145-164.

26. Greenburg JA: The use of barbed sutures in obstetrics and gynecology. Rev Obstet Gynecol 2010, 3:82-91.

27. Mulholland RS, Paul MD: Lifting and wound closure with barbed sutures. Clin Plastic Surg 2011, 38:521-535.

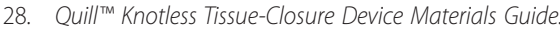
http://www.angioedupro.com/Quill/index.php?ID=Photos

29. Leung JC, Ruff GL, King MW, Dattilo PP Jr: Barbed, bidirectional surgical sutures. In Medical Textiles and Biomaterials for Healthcare: 8-9 July 2003. Edited by Anand SC, Kennedy JF, Miraftab M, Rajendran S. Cambridge: Woodhead Publishing in Textiles; 2006:395-403. http://www.angioedupro. com/Quill/journals/Leung\%20JC\%20-\%20Recent\%20advances\%20p62.pdf.

30. Shermak MA, Mallalieu J, Chang D: Barbed suture impact on wound closure in body contouring surgery. Plast Reconstr Surg 2010, 126:1735-1741.

31. Alessandri F, Remorgida V, Venturini PL, Ferrero S: Unidirectional barbed suture versus continuous suture with intracorporeal knots in laparoscopic myomectomy: a randomized study. J Minim Invasive Gynecol 2010, 17:725-729.

32. Zaruby J, Gingras K, Taylor J, Maul D: An in vivo comparison of barbed suture devices and conventional monofilament sutures for cosmetic skin closure: biomechanical wound strength and histology. Aesthetic Surg J 2011, 31:232-240

33. Ting NT, Moric MM, Della Valle CJ, Levine BR: Use of knotless suture for closure of total hip and knee arthroplasties. J Arthroplasty 2012. 127:1783-1788.

34. Woodley CM, Wagner KA, Bryson AJ: Performance assessment of bi-directional knotless tissue-closure device in juvenile Chinook salmon surgically implanted with acoustic transmitters, 2009. Pacific Northwest National Laboratory, Richland, Washington: Final Report; 2012.

35. Woodley CM, Carpenter SM, Carter KM, Wagner KA, Royer IM, Knox KM, Kim JA, Gay ME, Weiland MA, Brown RS: Surgically implanted JSATS micro-acoustic transmitters effects on juvenile Chinook salmon and steelhead tag expulsion and survival. Pacific Northwest National Laboratory, Richland, Washington: Final Report; 2011

36. Liedtke TL, Gee LP, Mesa MG, Beeman JW, Elliot DG, Conway CM: Evaluation of predator avoidance ability, tag loss, and tissue response of acoustic-tagged juvenile salmonids. In Comparative Performance of Acoustic-Tagged and Passive Integrated Transponder-tagged Juvenile Salmonids. Edited by Hockersmith EE, Brown RS, Liedtke TL. Portland District: Report of the National Marine Fisheries Service, Pacific Northwest National Laboratory, and U.S. Geological Survey to the U.S. Army Corps of Engineers; 2008

37. Frost DA, McComas RL, Sandford BP: The effects of a surgically implanted microacoustic tag on growth and survival in subyearling fall Chinook salmon. Trans Am Fish Soc 2010, 139:1192-1197.

38. Bjarnsholt T, Kirketerp-Møller K, Jensen PØ, Madsen KG, Phipps R, Krogfelt $K$, Høiby N, Givskov M: Why chronic wounds will not heal: a novel hypothesis. Wound Repair Regen 2007, 16:2-10.

39. van Rijssel EJ, Brand R, Admiraal C, Smit I, Trimbos JB: Tissue reaction and surgical knots: the effect of suture size, knot configuration, and knot volume. Obstet Gynecol 1989, 74:64-68.

40. Ingle NP, King MW: Optimizing the tissue anchoring performance of barbed sutures in skin and tendon tissues. J Biomech 2010, 43:302-309.

41. Summerfelt RC, Smith LS: Anesthesia, surgery, and related techniques. In Methods for Fish Biology. Edited by Schreck CB, Moyle PB. Bethesda, MD: American Fisheries Society; 1990:213-263.

doi:10.1186/2050-3385-1-9

Cite this article as: Woodley et al:: Performance assessment of bidirectional knotless tissue-closure devices in juvenile Chinook salmon surgically implanted with acoustic transmitters. Animal Biotelemetry 2013 1:9.

\section{Submit your next manuscript to BioMed Central and take full advantage of:}

- Convenient online submission

- Thorough peer review

- No space constraints or color figure charges

- Immediate publication on acceptance

- Inclusion in PubMed, CAS, Scopus and Google Scholar

- Research which is freely available for redistribution 